\title{
A BRIEF NOTE ON TRANSLITERATION AND OUR EDITORIAL POLICY
}

My editors at Cornell and Northern Illinois University Presses and I have decided against a "pure" recreation of the previously published essays in this volume in order to maintain consistent editorial conventions. Nevertheless, I have resisted the temptation to revise my earlier essays to update any new opinions that I may have. Issues of consistency were particularly pressing in chapters 2 and 13, which were originally published in Great Britain. Therefore, we have made small alterations to conform those texts with American editorial and spelling conventions. We have also changed all passages transliterated from Russian to conform to the most widely accepted transliteration system in the United States-the Library of Congress system. 
